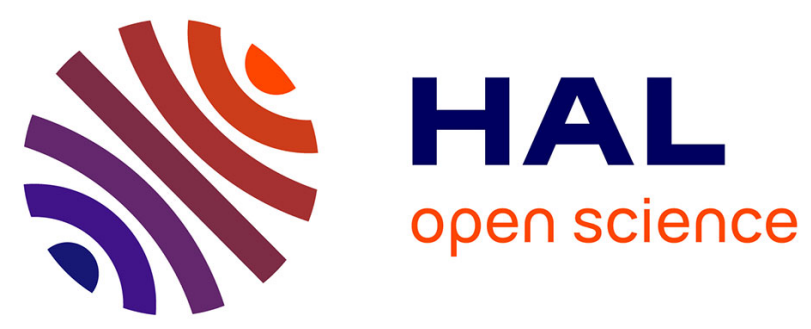

\title{
STRUCTURAL CHARACTERIZATION OF HIGH VALENT INTERMEDIATES IN HORSERADISH PEROXIDASE
}

\author{
J. Penner-Hahn, K. Smith Eble, J. Dawson, K. Hodgson
}

\section{- To cite this version:}

J. Penner-Hahn, K. Smith Eble, J. Dawson, K. Hodgson. STRUCTURAL CHARACTERIZATION OF HIGH VALENT INTERMEDIATES IN HORSERADISH PEROXIDASE. Journal de Physique Colloques, 1986, 47 (C8), pp.C8-1137-C8-1142. 10.1051/jphyscol:19868221 . jpa-00226134

HAL Id: jpa-00226134

https://hal.science/jpa-00226134

Submitted on 1 Jan 1986

HAL is a multi-disciplinary open access archive for the deposit and dissemination of scientific research documents, whether they are published or not. The documents may come from teaching and research institutions in France or abroad, or from public or private research centers.
L'archive ouverte pluridisciplinaire HAL, est destinée au dépôt et à la diffusion de documents scientifiques de niveau recherche, publiés ou non, émanant des établissements d'enseignement et de recherche français ou étrangers, des laboratoires publics ou privés. 
STRUCTURAL CHARACTERIZATION OF HIGH VALENT INTERMEDIATES IN HORSERADISH PEROXIDASE

\author{
J.E. PENNER-HAHN, K. SMITH EBLE* ; J.H. DAWSON* and \\ K.O. HODGSON ${ }^{*}$ \\ Department of Chemistry, The University of Michigan, Ann Arbor, \\ MI 48109-1055, U.S.A. \\ * Department of Chemistry, The University of South Carolina, \\ Columbia, SC 29208, U.S.A. \\ " Department of Chemistry, stanford University, stanford, \\ CA 94305, U.S.A.
}

\begin{abstract}
Extended X-ray absorption fine structure and X-ray absorption near edge structure spectroscopies have been utilized to determine the structural environment of the heme iron sites in horseradish peroxidase compounds $I$ and II. For comparison, analogous studies have been undertaken on putative ferryl, Fe(IV)=0, porphyrin modeI compounds and on crystallographically characterized $\operatorname{Cr}($ IV $)=0$ and $\mathrm{Cr}(\mathrm{V})=\mathrm{N}$ porphyrins. The present work demonstrates unambiguously that a short, ca. $1.64 \AA$, Fe-O bond length is present both in HRP Compounds I and II and in their synthetic analogues. Edge spectra show the oxidation state of these high-valent species to be $\mathrm{Fe}$ (IV) or greater. These structures are consistent only with an oxoferryl ( $\mathrm{Fe}=0$ ) complex as the active oxygen species of horseradish peroxidase. The structural details and their implications for heme protein mediated oxygen activation are discussed.
\end{abstract}

\title{
INTRODUCTION
}

Horseradish peroxidase is a heme-containing enzyme that catalyzes the oxidation of phenolic substrates, utilizing hydrogen peroxide as the ultimate electron acceptor. The resting form of HRP contains a high-spin ferric heme. During the catalytic cycle, HRP is initially oxidized by two electrons to a green species known as Compound I (HRP-I). One electron reduction of HRP-I yields the red species known as Compound II (HRP-II), that retains one oxidizing equivalent above the resting enzyme.

The peroxidases are of interest as paradigms of heme-mediated activation of the $0_{2}$ unit, and the intermediates in the HRP reaction cycle have been subjected to extensive physical and chemical characterization [1]. As part of a continuing program to characterize the mechanisms of heme mediated oxygen activation, we have undertaken an X-ray absorption spectroscopy (XAS) study of the high-valent intermediates formed during the catalytic cycle of horseradish peroxidase.

The resting form of HRP contains a five-coordinate heme, with the fifth coordination site occupied by an axial imidazole ligand [2]. HRP I is two oxidation equivalents above the ferric resting state and therefore formally contains Fe(V). Magnetic susceptibility measurements [3] indicate that there are three unpaired electrons $(S=3 / 2)$ in HRP.I. This has been explained by ferromagnetic coupling of low-spin $\mathrm{Fe}(\mathrm{IV})(\mathrm{S}=1)$ to a porphyrin $n$-cation radical $(S=1 / 2)$. Consistent with this 
assignment is the similarity of the optical spectrum of BRP-I and those of synthetic porphyrin $\pi$-cations [4]. Investigations of HRP-I by NMR [5] and ENDOR [6] as well as iterative extended Huckel (IEH) calculations [7] all favor the $\pi$-cation radical formulation.

HRP-II is formed by one electron reduction of HRP-I and is therefore formally $\mathrm{Fe}$ (IV). The Mössbauer spectra of HRP-I and HRP-II are very similar and are different from that of the ferric enzyme [8], supporting the assignment of $\mathrm{Fe}$ (IV) for both of the oxidized compounds. Isotopic labeling studies have shown unequivocally that HRP-I and HRP-II contain one atom of oxygen [9], but the protonation state of this oxygen has been a matter of controversy. HRP-I is generally believed to Ggntain an oxo (double bonded oxygen) ligand, an assignment which is supported by 19 ENDOR measurements [10]. Both oxo and hydroxyl ligation have been proposed for HRP-II, however recent NMR [11] and resonance Raman [12] studies appear to be consistent only with the oxo assignment.

Our initial XAS studies of HRP [13] showed that both high valent HRP species contain highly oxidized iron porphyrins ( $\mathrm{Fe}(\mathrm{III})$ ) and a coordination environment that could only be modeled by inclusion of a short $(\sim 1.6 \AA)$ Fe-0 interaction. A key feature of this work was the finding that HRP-I and HRP-II, and related compound I and Compound II models, had identical structures from the perspective of XAS. Recently, Chance et al. have reported the results of an XAS study of HRP-I, HRP-II, and related catalase complexes [14]. While confirming our results for HRP-I, this work suggested that HRP II has a significantly different structure, characterized by a much longer (1.93 $\AA$ ) $\mathrm{Fe}-0$ interaction. On the basis of this metric information, Chance et al. proposed a peroxidase mechanism involving formation of a double bonded $(\mathrm{Fe}=0)$ complex in HRP-I and, on reduction, a single bonded Fe-O complex in HRP-II. This mechanism is in conflict with findings from our laboratories $[13,15]$ and with other evidence [8] that the Fe sites in HRP-I and HRP-II are very similar. In addition, this new mechanism, which would indicate hydroxyl ligation in HRP-II, contradicts a substantial body of evidence $[11,12,16]$ suggesting oxo ligation in this complex. We present here a summary of both our initial studies [13] and our more recent XAS investigations [15] of the high valent intermediates in HRP.

\section{EXPERTMENTAL}

HRP was prepared and concentrated as described previously [13]. HRP-I was prepared by addition of ethyl hydroperoxide to ferric HRP, giving a characteristic green solution. Addition of one equivalent of reductant (ascorbate) to HRP-I resulted in formation of a red solution, characteristic of HRP-II. Sample composition was verified using UV-visible absorption spectroscopy at $4^{\circ} \mathrm{C}$ on a diluted aliquot. By the UV-visible criterion, sample homogeneity was greater than 95\% for both HRP-I and HRP-II. After preparation, the samples were frozen and maintained at $-80^{\circ} \mathrm{C}$ throughout data collection. Following completion of XAS data collection, the protein samples were immediately reanalyzed by UV-visible absorption spectroscopy; no significant degradation in sample homogeneity was observed. High valent iron porphyrin model compounds with formal oxidation states $\mathrm{Fe}$ (IV) and $\mathrm{Fe}(\mathrm{V})$ are illustrated schematically (1-3, right). These were prepared by A.L. Balch and coworkers and J.T. Groves and coworkers according to literature procedures [17]. As a complement to the $\mathrm{Fe}$ studies, the crystallographically characterized high-valent $\mathrm{Cr}$ porphyrins (TTP) $\mathrm{Cr}$ (IV)O (4) and (TTP) $\operatorname{Cr}(V) N$ (5) were also studied. Data were calibrated, averaged, and reduced as

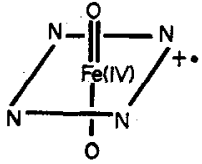

1

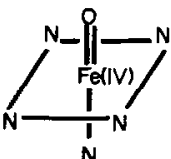

$\underline{2}$

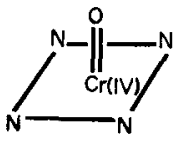

$\underline{4}$

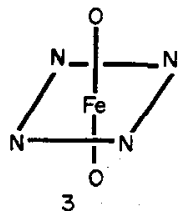

$\underline{3}$

described previously [18]. The normalized, background subtracted data were converted from energy $\mathrm{E}$ to photoelectron wave-vector $\underline{k}=\left[\left(2 \mathrm{~m} / \mathrm{h}^{2}\right)\left(\mathrm{E}-\mathrm{E}_{0}\right)\right]^{172}$ with $\mathrm{E}_{0}$ $=7130 \mathrm{eV}(\mathrm{Fe})$ or $6010 \mathrm{eV}(\mathrm{Cr})$. 
The two different procedures used for data analysis are described in detail elsewhere [15]. In brief, the first method is an empirical procedure utilizing parameterized amplitude and phase functions determined from model compounds. In this method, the number of scatterers and the absorber-scatterer distance are adjusted as variable parameters [19]. The second analysis procedure is similar to Teo's FABM method [20], in which ab initio parameters are used, with the scale factor and $\Delta E_{0}$ empirically optimized by comparison with model compounds.

\section{RESULTS AND DISCUSSION}

The XANES spectra for resting HRP, HRP-I, 1, 2, and 3 are shown in Figure 1. In each case, the principal absorption discontinuity occurs at a higher energy than that found for $\mathrm{Fe}$ (III) porphyrins. This suggests [13] the presence of $\mathrm{Fe}$ (IV) in all four species. The spectra for HRP-I and HRP-II (not shown) are superimposable within the noise level of the data, and those for 1 and 2 are quite similar. These spectra all lack the intense pre-edge feature frequently associated with metal-oxo porphyrins, however recent calculations [21] confirm that the XANES spectra for HRP$I$, HRP-II, 1 , and 2 are consistent with an $\mathrm{Fe}(\mathrm{IV})=0$ (porphyrin) structure. The similarity of these XANES spectra demonstrates that the four different Fe sites must have similar structures. This interpretation is supported by the similarity in the EXAFS spectra of these compounds. As shown in Fig. 2, the EXAFS spectra for HRP-I, HRP-II, 1, 2, 4, and 5 are all qui te similar, with a characteristic principal maximum at $k \sim 6.1 \AA^{-1}$. The EXAFS spectrum for 3 , with a maximum at $\underline{k} \sim 6.4 \AA^{-1}$ is noticeably different over the range $\underline{k} \sim 5-9 \AA^{-1}$.

Fig. 1. XANES spectra for resting HRP ( $($, top-left $), 1(-)$, HRP-I $(--), 2(--\bullet)$, and 3 (-, bottom-right). Spectrum for HRP-II (not shown) is identical to that for HRP-I, within the noise of the data. [Reproduced from Ref. 13].

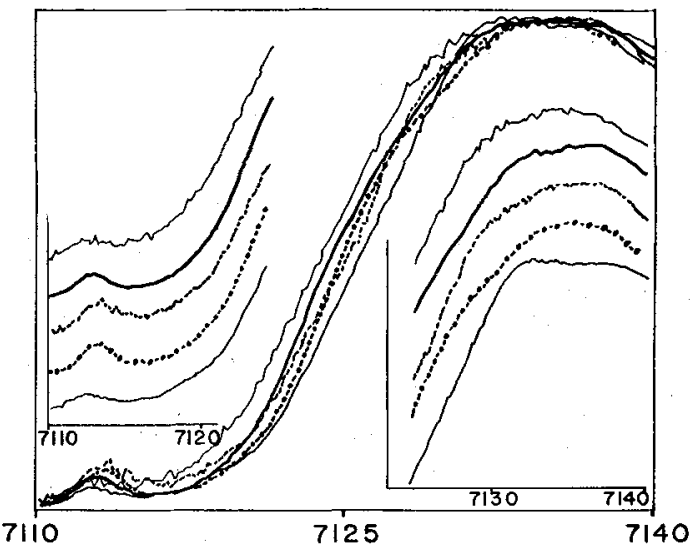

Energy (ev)

The qualitative similarity of the XANES and EXAFS spectra for HRP-I, HRP-II, $1,2,4$, and 5 suggests that the structures of the metal sites in all of these species must be very similar. In order to test this interpretation, we have carried out a complete curve fitting analysis of the EXAFS data. The resulting structural parameters are given in Table I. For all species except 3 , the mean-square deviation between the data and the fit decreased 2-fold or more for 2 shell fits $(\mathrm{N}+0)$ compared to 1 shell ( $\mathrm{N}$ only). In contrast, the EXAFS data for 3 were well modeled using only a single shell of nitrogen, with a relatively short $(1.92 \AA) \mathrm{Fe}-\mathrm{N}$ distance. Attempts to improve this fit by including a shell of oxygen at a short distance resulted in the disappearance $(\sigma \rightarrow \sim 1)$ of either the $N$ or the 0 shell. These fitting results, together with X-ray edge spectra indicating a highly symmetric $\mathrm{Fe}$ environment, are most consistent with a symmetric 6-coordinate structure for 3, with an average Fe-ligand distance of $1.92 \AA$. The Fe-N(porphyrin) distance expected for a 6 -coordinate porphyrin is $\sim 1.98 \AA$. In order to obtain the observed average Fe-ligand distance, this would require an $\mathrm{Fe}-0$ axial distance of $\sim 1.80 \AA$ in 3 . This is consistent with recent NMR and Mössbauer data showing that 3 is in fact a bismethoxy $\mathrm{Fe}$ (IV) porphyrin [22]. 

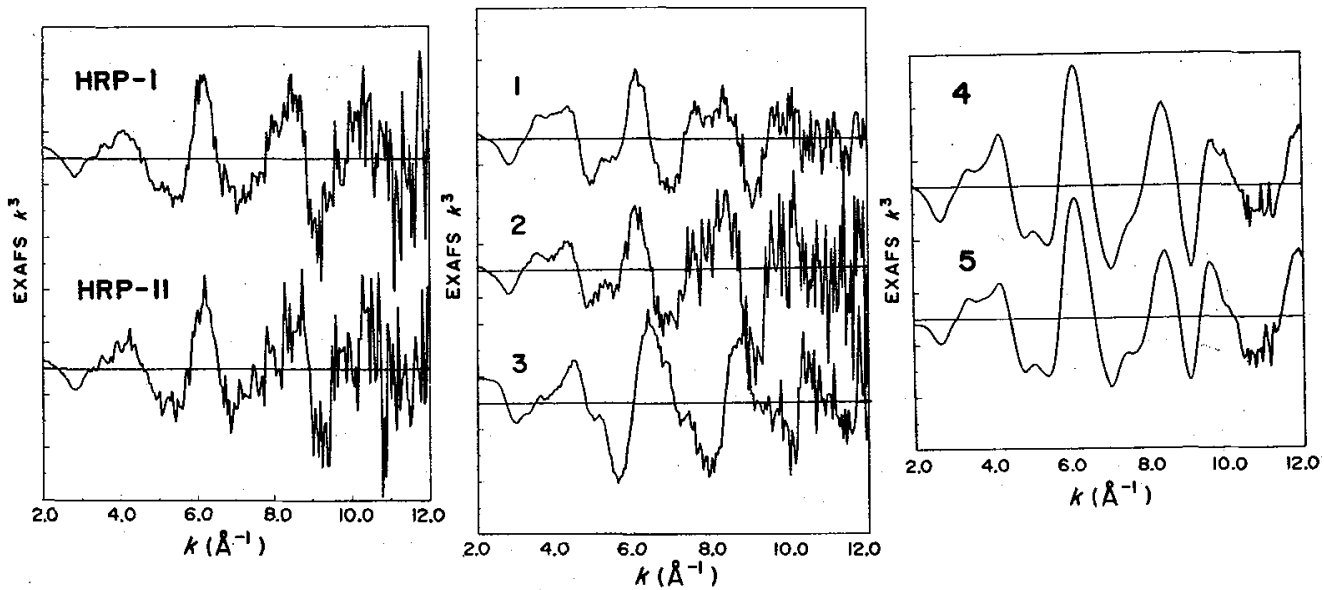

Fig. 2. EXAFS spectra for HRP-I, HRP-II, 1, 2, 3, 4, and 5 .

Table I. Iron-Porphyrin Structural Parameters

\begin{tabular}{|c|c|c|}
\hline \multirow[b]{2}{*}{ Sample } & \multicolumn{2}{|c|}{ EXAFS ${ }^{a}$} \\
\hline & $M-N$ & $M-0$ \\
\hline & $\overline{2.03}$ & $1.62-1$ \\
\hline 2 & 2.03 & $1.64-1$. \\
\hline 3 & 1.92 & \\
\hline 4 & 2.01 & 1.52 \\
\hline $\begin{array}{l}5 \\
6\end{array}$ & 2.02 & 1.49 \\
\hline HRP-I & 2.00 & \\
\hline HRP $-I]$ & 2.00 & \\
\hline
\end{tabular}

Crys tallography

M-N M-O

$\begin{array}{ll}2.03 & 1.57 \\ 2.04 & 1.57 \\ 2.005 & 1.604\end{array}$

2.005 . 1.604

EXAFS results are the extreme values obtained by any of the fitting methods employed. $M-N$ is the average of $M-N$ (pyrrole) and $M$-axial atom bond lengths. M-0 is the $M=0$ ( $M=N$ for 5) bond length. Errors in $M-0$ for 4 and 5 results from errors in $\mathrm{E}$ [15]. If $\mathrm{E}$ is allowed to vary, $\mathrm{M}-0$ for 4 and 5 changes to the crystallographic value; no such change in $M-0$ occurs for the Fe compounds.

The most significant result of this work is the determination of the presence and length of the Fe-O bond in HRP-I and HRP-II and in their high-valent Fe porphyrin models. Our EXAFS results show that this distance is $1.64 \pm 0.03 \AA$ for all four postulated ferryl species. The corresponding $\mathrm{Cr}-0$ distance in the chromyl analog 4 [23] and in oxo- $\operatorname{Cr}(V)$ (salen) complexes [24] is 1.55-1.57 $\AA$. An increase of ca. $0.08 \mathrm{~A}$ in the M-0 distance is completely consistent with the addition of two $3 \mathrm{~d}$ electrons in moving from $\mathrm{Cr}$ (IV) to $\mathrm{Fe}(\mathrm{IV})$. Additional support for our proposed structures is found in the recent preparation and preliminary structural characterization of a new HRP-II model, Fe(IV)(0)(THF)(TPivP), 6 [25]. Although this structure suffers from disorder, it indicates that the ferryl Fe=0 bond length

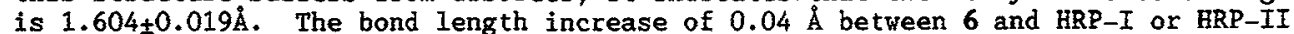
is only marginally significant, however this may reflect the greater strength of the distal Fe-N(imidazole) bond in HRP relative to the $\mathrm{Fe}-0$ (THF) bond in 6 .

Our finding that HRP-I and HRP-II are very similar structurally is at odds with the findings of Chance et al. [14] who suggest that HRP-II has a much longer, 1.93 $\AA$, Fe-0 single bond. The two proposed structures for HRP-I are very similar, thus ruling out different data analysis procedures as accounting for the discrepancy in HRP-II structures. We note that the EXAFS spectra for HRP-I and HRP-II shown in Fig. 4 of Ref. 14 are noticeably different, in contrast to the similarity which we observe (Fig. 2). The reasons for this difference remain to be resolved, however we 
note that our results are consistent with the suggestion (vide supra) that the principle difference between HRP-I and HRP-II is the presence of a porphyrin $\pi-$ cation in the former. In particular, the similarity of the Mössbauer spectra [8] and the X-ray absorption edge spectra of HRP-I and HRP-II [13] suggests that the Fe environment in these species must be very similar. Additional evidence for the similar structures is provided by resonance Raman spectroscopy, which shows that HRP-I [26] and HRP-II [12] have nearly identical Fe-0 stretching frequencies. Finally we note that the only high-valent Fe porphyrin complex to have been crystallographically characterized (complex 6 , above) is in fact a model for HRP-II. The Fe-0 bond length in 6 is consistent with our results and inconsistent with those of Chance et al.

The reduction of HRP-I is known to occur with concomitant uptake of one proton, however our results show that this does not result in protonation of the oxo ligand. This is not surprising, since the $\mathrm{Fe}(\mathrm{IV})=0$ moiety is unlikely to be a strong base. A possible location for this added proton is suggested by recent resonance Raman results [27] which indicate the presence of an ionizable group (probably imidazole) within hydrogen-bonding distance of the oxo ligand. A proton in this location would then be available when HRP-II is converted, with the uptake of an electron and a second proton, to ferric HRP and water (Figure 3 ). The fact that HRP-I and HRP-II have similar iron-site structures may facilitate rapid reduction of HRP-I during the catalytic cycle, since there would be only a small reorganizational energy barrier to this reaction. The apparently pervasive nature of short $\mathrm{Fe}=0$ bonds in high valent Fe porphyrins (HRP-I, HRP-II, 1, and 2), together with the similar reactivity of HRP and $P-450$ on treatment with peroxide, suggests that a similar ferry $1(\mathrm{Fe}=0)$ complex may be the active oxygen species in P-450.
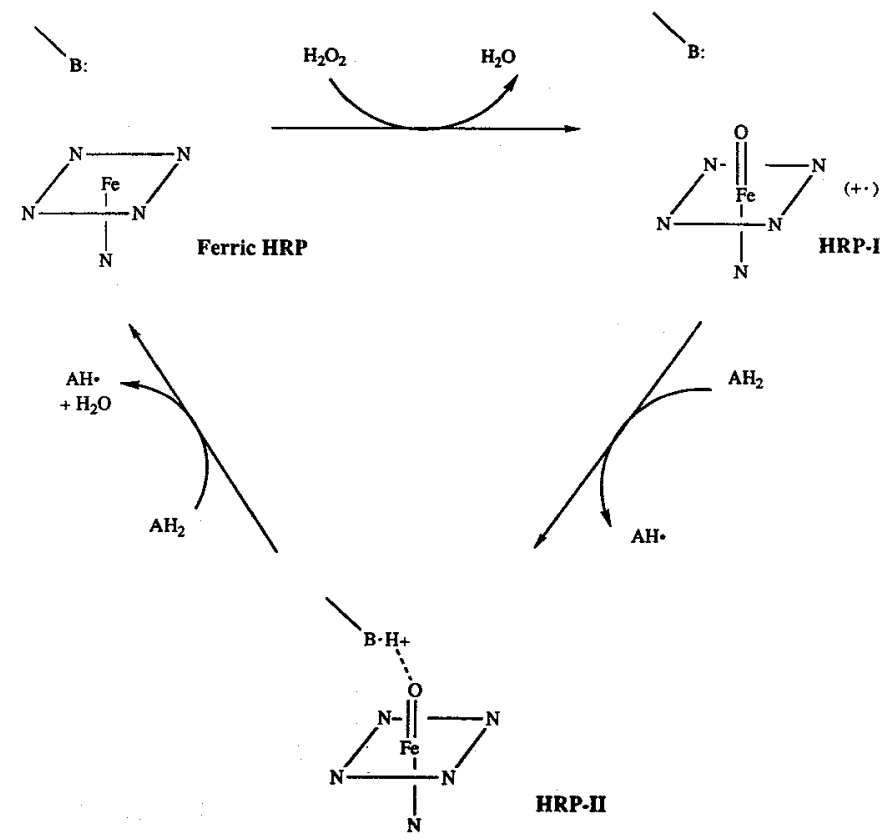

HRP-II

Fig. 3. Schematic illustration of HRP catalytic cycle consistent with XAS results.

\section{ACRNOULBDGEMENTS}

This work was supported by the National Science Foundation (CHE 85-08115 to KOH and PCMJ82-16799 to JHD) and a Camille and Henry Dreyfus Distinguished Young Faculty Award (to JEPH). JHD is a Camille and Henry Dreyfus Teacher/Scholar, an Alfred P. Sloan Research Fellow, and a recipient of a National Institutes of Health Research 
and Career Development Award (AM-01123). Synchrotron radiation was provided by the Stanford Synchrotron Radiation Laboratory which is supported by the United States Department of Energy and the National Institutes of Health through the Biotechnology Resource Program in the Division of Research Resources. We wish to thank Professors A.L. Balch and J.T. Groves for providing model compounds and Professor G.T. Babcock for communication of results prior to publication.

\section{REFERENCES}

1. (a) Dunford, H.B.; Stillman, J.S.Coord. Chem. Rev. 1976, 19, 187-251. (b) Hewson, W.D.; Hager, L.P. In The Porphyrins; Dolphin, D., Ed.; Academic Press: New York, 1979; Vol. 7, pp 295-332. (c) Frew, J.E.; Jones, P. Adv. Inorg. Bioinorg. Mech., 1984, 3, 175.

2. Poulos, T.G.; Finzel, B.C.; Gunsalus, I.C.; Wagner, G.C.; Kraut, J. Biol. Chem., 1985, 260, 16122-16130.

3. Theorel1, H.; Ehrenberg, A. Arch. Biochem. Biophys., 1952, 41, 442-461.

4. Dolphin, D.; Forman, A.; Borg, D.C.; Fajer, J.; Felton, R.H. Proc. Natl. Acad. Sci., U.S.A. 1971, 68, 614-618.

5. LaMar, G.; deRopp, J.S.; Smith, K.M.; Langry, K.C. J. Biol. Chem., 1981, 256, 237-243.

6. Roberts, J.E.; Hoffman, B.M.; Rutter, R.; Hager, L.P. J. Biol. Chem. 1981, $256,2118-2121$.

7. Hanson, L.K., Chang, C.K.; Davis, M.S.; Fajer, J. J. Am. Chem. Soc. 1981, 103, $663-670$.

8. (a) Schulz, C.E.; Devaney, P.W.; Winkler, H.; Debrunner, P.G.; Doan, N.; Chiang, R.; Rutter, R.; Hager, L.P. FEBS Lett. 1979, 103, 102-105. (b) Moss, T.H.; Ehrenberg, A.; Bearden, A.J. Biochemistry, $1969,8,4159-4162$.

9. (a) Schonbaum, G.R.; Lo, S. J. BioI. Chem., 1972, 247, 3353-3360. (b) Adediran, S.A.; Dunford, H.B. Eur. J. Biochem. 1983, 132, 147-50.

10. Roberts, J.E.; Hoffman, B.M.; Rutter, R.; Hager, L.P. J. Am. Chem. Soc. 1981, $103,7654-7656$.

11. LaMar, G.N.; de Ropp, J.S.; Latos-Grazynski, L.; Balch, A.L.; Johnson, R.B.; Smith, K.M.; Parish, D.W.; Cheng, R.-J. J. Am. Chem. Soc. 1983, 105, 782-787.

12. Terner, J.; Sitter, A.J.; Reczek, C.M. Biochim. Biophys. Acta 1985, 828, 73-80.

13. Penner-Hahn, J.E.; McMurry, T.; Renner, M.; Latos-Grazynski, L.; Eble, K.S. ; Davis, I.M.; Balch, A.; Groves, J.T.; Dawson, J.H.; Hodgson, K.0. J. Biol. Chem. 1983, 258, 12761-12764.

14. Chance, B.; Powers, L.; Ching, Y.; Poulos, T.; Schonbaum, G.R.; Yamazaki, I.; Paul, K.G. Arch. Biochem. Biophys. 1984, 235, 596-611.

15. Penner-Hahn, J.E.; Eble, K.S.; Renner, M.; Balch, A.L.; McMurry, T.J.; Groves, J.T.; Dawson, J.H.; Hodgson, K.0. J. Am. Chem, Soc., 1986, in press.

16. Hanson, L.K., personal communication.

17. (a) Chin, D.H.; LaMar, G.N.; Balch, A.L. J. Am. Chem. Soc. 1980, 102,4344-4350. (b) Chin, D.H.; Balch, A.L.; LaMar, G.N. J. Am. Chem. Soc. 1980, 102, 14461448. (c) Groves, J.T.; Haushalter, R.C.; Nakamura, M.; Nemo, T.E.; Evans, B.J. J. Am. Chem. Soc. 1981, 103, 2884-2886. (d) Groves, J.T.; McMurry, T.J. Revista Portuguesa de Quimica 1985, 27, 102-103.

18. Hahn, J.E.; Hodgson, K.0.; Andersson, L.A.; Dawson, J.H. J. Biol. Chem., $1982,257,10934-10941$.

19. Cramer, S.P.; Hodgson, K.0. Prog. Inorg. Chem., 1979, 25, 1-39.

20. Teo, B.K.; Antonio, M.R.; Averill, B.A. J. Am. Chem. Soc. 1983, 105, 3751-3762.

21. Penner-Hahn, J.E.; Benfat to, M.; Hedman, B.; Takahashi, T.; Doniach, S.; Groves, J.T.; Hodgson, K.O. Inorg. Chem., 1986, in press.

22. (a) Groves, J.T.; Quinn, R.; McMurry, T.J.; Nakamura, M.; Lang, G.; Boso, B. J. Am. Chem. Soc. 1985, 107, 354-360. (b) Groves, J.T.; Gilbert, J.A. Inorg. Chem. 1986, 25, 125-127.

23. Groves, J.T.; Kruper, W.J. Jr.; Haushalter, R.C.; Butler, W.M. Inorg. Chem. $1982,21,1363-1368$.

24. Srinivasan, K.; Kochi, J. Inorg. Chem. 1985, 24, 4671-4679.

25. Schappacher, M.; Weiss, R.; Montiel-Montoya, R.; Trautwein, A.; Tabard, A. J. Am. Chem. Soc. 1985, 107, 3736-3638.

26. Babcock, G.T., personal communication.

27. Sitter, A.J.; Reczek, C.M.; Terner, J. J. Biol. Chem., 1985, 260, 7515-7522. 